\title{
Professional Support, London: the professional development unit supporting practitioner well-being, refreshment, remediation and revalidation
}

\author{
Julia Whiteman , Penny Morris, Helen Halpern
}

\begin{abstract}
London's Professional Support Unit (PSU) was launched in April 2012 at a time when changes and financial pressures across the health service were placing considerable demand on the medical and dental workforce. At the same time the infrastructure to support medical revalidation was established. The PSU provides developmental support to clinicians across London in all career grades and specialities, to sustain and restore them to contribute effectively to health service delivery across the capital. The costs of medical training are high. Maintaining doctors at work has to be cost effective. Clinicians in multicultural London require diverse resources, as increasing numbers have trained abroad.
\end{abstract}

The PSU offers a holistic, tailor-made approach to professional and personal development with a range of resources and approaches. It provides proven high quality educational interventions, creating a linked and integrated service, providing clinicians with new opportunities. Access is by self-referral with resources targeted at those going through transitions in their professional lives, as well as those who have specific developmental needs.

A collaborative approach across the PSU and its education and governance communities ensured the provision of personal support to over 1300 clinicians in its first year, together with interdisciplinary group learning opportunities. Online materials were created to assist individuals, workplace groups and a broad network of support and expertise. To maximise the effectiveness of the service, learning events were also held for those working within the PSU.

In commending the PSU and its positive impact, the General Medical Council has recommended the model be shared nationally. At the same time the Londonâ $\mathrm{C}$ s three Local Education Training Boards have recommended that the PSU expand to encompass a more diverse range of professional groups. Our challenge is how to extend such flexible, responsive and values-based support across the workforce, given stringent financial pressures.

\section{Problem}

Our health workforce is required to respond to service delivery change and pressures for improvements in quality, whilst embedding compassionate care (1). During ongoing financial restraints, maintaining morale is a challenge.

Strengthened medical appraisal has identified the need for clinicians to access specific interventions beyond simply addressing clinical knowledge and skills to ensure they are fit for purpose in all areas, including linguistic competence and ensuring that their own health does not pose a risk to patients and colleagues. As appraisal and revalidation processes develop, it is anticipated that an increasing number of doctors will identify learning needs which will require specialist input.

In addition there are a group of doctors who require remediation (2). The White Paper 'Trust, Assurance and Safety' (3), stated that remediation should be offered to doctors whose fitness to practise is compromised. This needs to be provided in a way that is both supportive to the clinician and educationally effective and robust, ensuring that patient safety is held as the highest priority
The London Deanery Professional Support Unit (PSU) offers a holistic, tailor-made approach to professional and personal development with a range of resources and approaches. The PSU aims to sustain and restore clinicians to contribute effectively without compromising patient safety. It is available to any doctor relating to a London Responsible Officer or any London dentist who wishes to use the resources. Access, by self-referral, is targeted at those going through transitions in their professional lives, as well as those who have specific developmental needs.

\section{Background}

Health service leaders are required to help shape a culture that will promote openness and compassionate care (1). Efforts to develop and disseminate excellence in communication and team working are helpful to sustain clinical leadership and improved ways of relating to patients, carers and families. Given it costs $£ 269,527$ to train a doctor in the UK to foundation level (4), endeavours to maintain doctors at work can and must be cost-effective.

Crucial factors that play a part in clinical performance are complex and interrelated, including biological, psychological and social 
factors (5). We recognise the contribution of organisational, political and financial contexts in cliniciansâcu understanding of their role in patient care and their experience of satisfaction at work. All these aspects can lead to situations where professional support is both necessary and highly valued.

The PSU's approach is supported by the General Medical Council (GMC) in Good Medical Practice (6, p.6): "You must regularly take part in activities that maintain and develop your competence and performance" and "You should be willing to find and take part in structured support opportunities offered by your employer or contracting body (for example mentoring). You should do this when you join an organisation and whenever your role changes significantly throughout your career."

The exact prevalence of underperforming doctors is uncertain as it is dependent on where the cut-off point is made and what processes are used for assessment (7). Increasing numbers of doctors are being identified as having performance concerns. This includes referrals to the General Medical Council (GMC) and the National Clinical Assessment Service (NCAS) and issues arising from appraisal, complaints and other clinical governance processes.

Remediation needs to balance the benefits of maintaining the doctor's career with the safety of patients, legal risks, and resources available (8). Primary Care organisations have traditionally provided some support, but the role of Postgraduate Deaneries, now Local Education Boards as sub-committees of Health Education England, has been very variable across geographical areas (8). The Department of Health Remediation Steering Group has recommended that a single organisation should provide advice and case-manage remediation to achieve a consistent approach (2). The Academy of Royal Medical Colleges Report on remediation stressed the importance of dealing with concerns early and providing quality assurance with good documentation throughout the remediation processes (9).

Many doctors will have a problem at some point in their career without this necessarily leading to a major performance concern. Problems may be related to issues such: health, relationships within the team at work or in the doctor's personal life, career decisions (especially at times of transition), minor complaints, crises of confidence to full-blown burnout and difficulties in managing worklife balance. As Kinnersley and Edwards (10) maintain, a package of intervention, with a range of services to provide any remediation and continuing support, is often needed.

\section{Baseline measurement}

Prior to 2012, some professional development services were being provided by the then London Deanery and partner organisations for trainees and some established clinicians, including: a Coaching and Mentoring service (11); a Careers service (12); Communication skills support through the Language and Communication Resource Unit (LaCRU), mainly for trainees (13) and Fresh Start courses, mainly for GPs (14, p 190-2); remediation support through case work and educational supervision (15); an Induction and Refreshment Scheme for EU and Returner GPs and the psychological support service at MedNet (16). These services were acknowledged to be of high quality, winning recognition internationally and awards, but there was little working across projects and the service was not as widely available and comprehensive as it needed to be. A series of discussions was held to define shared ethos, approaches and vision for an integrated, expanded, improved professional support service.

\section{Design}

In autumn 2011 a draft proposal was drawn up for a unit (PSU) to provide an expert shared service of resources to support the professional development of clinicians working in the capital. It would bring together the professional development resources of proven high quality that the then London Deanery offered to trainees and selected groups of doctors, making these resources available across all career stages to doctors and dentists across London and recognising a potential wider remit of the unit.

We invited stakeholders across London to discuss with us the proposed outline for the scope and function for the PSU. This popular event resulted in unequivocal support for taking forward our proposals. We asked stakeholders what success might look like in a year to try to develop a shared vision of what we were working towards.

We wrote up the consultation event (17), revised the framework in response to feedback and continued to work with key stakeholders to ensure we shaped the service according to need and maintained a high profile. For our launch in April 2012 we developed eyecatching banners and leaflets to promote our resources and ensured that these matched the colours and imagery of the developing PSU website pages

http://www.londondeanery.ac.uk/professionaldevelopment/professional-sup....

The aims of the PSU were to respond to the following particular health service needs:

- Supporting Responsible Officers and service and education providers to meet the challenges of medical revalidation due for launch in late 2012, including the requirements for early and effective remediation to meet needs identified through the strengthened appraisal process so that doctors are able to progress successfully through revalidation.

- A widespread recognition of the need of better support for clinicians as they progress through their careers from undergraduate level to retirement to enable them to realise and sustain their full potential, manage their talents and enable them to maximise their contribution to quality health care delivery.

- Improved assessment processes for doctors and dentists in postgraduate training were leading to the identification of increased numbers of trainees in difficulty, and consequently the need for expert advice, guidance and management.

- London has significant numbers of clinicians from the EU and 
international medical graduates. Language, communication skills and cultural issues can present a barrier to effective learning, teaching and performance for these clinicians hence additional support in this area would support them to contribute fully, practise more safely and have fulfilled careers in London.

- The need to identify opportunities to achieve 'value for money' by offering a pan-London approach to support the provider landscape.

From our initial stakeholder consultation in autumn 2011 onwards we have adopted a clinician-led approach in the development, delivery and access of resources which is entirely by self-referral. We aim to provide a flexible, responsive service through working with an individual's needs, taking into account the wider context of their personal and professional lives. Our ethos is one of encouraging autonomy and learning from reflection, so that clinicians are empowered to build on their strengths to achieve their aspirations, as well as fulfil their learning needs. Our policy of encouraging clients to initiate the contact with the PSU, rather than being referred, is based on the transtheoretical model of change (18). This means that when doctors approach us it is more likely that they will remain engaged and make changes as they have already moved beyond the stage of 'pre-contemplation' of action, i.e., they have already made a move themselves.

The resources we offer include:

- Careers Support from a team of careers professionals, headed by an occupational psychologist. The support on offer spans brief careers guidance sessions through to in-depth careers counselling where doctors are facing career decisions complicated by significant health and/or performance concerns.

- Coaching and Mentoring from an experienced team of trained and quality assured coaches and mentors. The service aims to embed coaching and mentoring as a culture in the health service by offering individuals and teams substantive and taster training. In 2011 the Deanery Coaching and Mentoring won the National Leadership and Innovation Agency for Healthcare award for 'best learning and development strategy'. The award recognised an outstanding contribution to human resource management and the tangible difference to patient care.

- Communication Skills Resources brings together successful approaches to improving communication with patients, families, carers and colleagues. These resources offer one-to-one and group support for identifying and addressing personal communication issues, including self-awareness, working effectively in partnership with others, language and communication skills, cultural understanding, and dealing with communication systems. Led by communication specialists and medical educators alongside patient voices (expert patient facilitators and specialist role players), these resources are also offered to workplaces, supervisors and Specialty Schools to develop 'Communication Champions' across London.

- Complex Cases provides support for doctors with concerns about their clinical performance. We provide guidance to doctors about constructing personal developments plans that are relevant, meaningful and achievable. This supports local clinical practice through experienced educational supervisors who make up our 'Network of Expertise'.

- Learning Development and Personal Effectiveness is a suite of interactive e-learning modules and podcasts designed to improve self-awareness and reflective practice and address issues of undermining and mental health in the workplace.

- MedNet offers confidential psychological support led by an experienced team of consultant psychiatrists and psychotherapists.

- Occupational Health offers advice to employers and educators about how best to access local occupational health services and is a model with potential for wider application (19).

- Return to Practice Schemes support all specialties and career grades. The philosophy is to provide a period of induction into the workforce after a break from clinical practice or for doctors new to UK practice, including a programme for refugee doctors. The Schemes can also be used to support remediation for doctors deemed through their appraisal/revalidation processes to need a period of retraining. All Schemes offer doctors up to 6 months in a supervised clinical placement appropriate for their career grades and specialty so that they gain confidence with working in the NHS of 2013, establish professional networks and learn about current approaches to practice.

\section{Strategy}

Improvement cycles

As soon as we launched in April 2012 we began a review of our resources in the light of feedback from clients and other stakeholders and sought to shape our services in response to this as a tangible demonstration of our commitment to work with the wider medical workforce across London. We produce regular, detailed reports (for more details of six, nine and 12 month reporting, see results section) for wide circulation and to inform our planning for resource provision.

Our website is the focus for our information and marketing and we have worked with users and other stakeholders to make that as accessible as possible with podcasts and other user information.

We have successfully sought opportunities to present and promote the PSU at conferences and other meetings, including contributing to induction programmes for clinicians across London.

\section{Results}

From the outset we established a system to monitor basic statistical information including services accessed, grade of staff utilising services and breakdown of unit activities. We published a report of these quarterly.

A target of 1000 new clients was set for the first year. Measuring 
the number of new clients accessing the service (growth trends) proved problematic as some clients accessed more than one service/activity. In order to identify a measure which effectively evaluated overall service growth, the number of first time events per service (new client encounters) has been used. This ensures consistency of monthly 'growth' data, although it under-reports the actual level of service activity such as clients attending webinars, one to one meetings, small group courses, study days, conferences etc.

By six months it was clear that the PSU was well on target for its provisional goal set of 1000 new events/encounters for the first year and at nine months the figure was exceeded. At 12 months we had provided for 1349 new encounters in all. New services have been introduced and fresh developments made in existing parts of the service. See PSU reports, available at http://www.londondeanery.ac.uk/professionaldevelopment/professional-sup....

With medical revalidation due to go live in December 2012 it was expected that activities and clients accessing resources would increase from April 2013. Yet there were uncertainties about the PSU's future with the changes happening across the NHS' architecture and cuts being made to funding streams. We therefore had to think of ways that we could manage an increasing demand without compromising quality. The approaches that we adopted included:

1. Investing in our network of clinical educators located in the NHS Trusts and primary care across London through workshops to increase knowledge, skills and awareness of factors that can influence a clinician's performance, from managing the legal aspects of PSU work to maintaining professional boundaries. In addition, our Communication Skills Resources now extend to a network of 'Communication Champions' in the workplace.

2. Developing a suite of e-learning modules on reflective practice, managing professional boundaries \& mental health in the workplace on our website under the banner of Learning, Development and Personal Effectiveness.

3. Offering more activities in group format rather than $1: 1$, both in face to face settings and via webinars. Topics include building career resilience through mindfulness, maintaining working equilibrium and improving work life balance, how to break bad news, improving English pronunciation.

4. In response to feedback from client information and stakeholders we have targeted efforts towards developing occupational health resources including an on-line fitness for work guide for medical managers, educational supervisors and clinicians themselves.

Further information on our activity can be found at http://www.londondeanery.ac.uk/professionaldevelopment/professional-sup...

Summary of PSU Activities April 2012 âdu March 2013
We have been developing a unique and comprehensive support service for doctors and dentists in London. We continue to review the service in response to feedback and offer supervision, educational development and quality assurance for the provider team.

At the outset we pledged to provide 1:1 support to 1000 clinicians across London within the first year. We achieved that target within the first nine months and provided personal support to 1349 clinicians by the year end.

We have received consistently positive feedback. Testimonials from Careers and Communication Resources clients are included in the uploaded PSU Feedback document.

As well as working directly with clients we have developed and delivered workshops about all aspects of professional support from managing ill health to awareness of the legal framework in complex casework with individual clinicians. Through this we have begun to

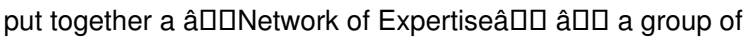
experienced educators from across all branches of medicine who work with us on one to one case management and also benefit from being part of the PSU wider network in their regular medical educator and clinical roles. Feedback from the Network is also included here.

A wide range of parties, including trainees, have contributed to the development of our services. We believe this helps to raise the profile of the PSUâUDs approaches to clinical performance including the challenges with language and cultural diversity across London and the impact health can have on a clinicianâCDs ability to perform to their full capability. For example, we are now involved in a detailed piece of work with our School of Psychiatry to provided work-based support to trainees who do not have English as their first language.

With the organisational changes in the NHS architecture the PSU participated in a review that encompassed all the London Deanery's Professional Development activities. Feedback from stakeholders (included in the uploaded document PSU Feedback) about the impact of the PSU confirms the strong place it has established for itself as a credible provider of professional development, remediation and rehabilitation services for London.

We have also included samples of feedback from our Mentoring and Communication Resources clients as part of our uploaded evidence about the project.

See supplementary file: ds $1696 . d o c x$

\section{Lessons and limitations}

We have learned that provision of support for clinicians striving to improve their practice benefits from an interrelated network of skilled and experienced practitioners who can share, develop and disseminate their own learning. This leads to support for clinicians who, whilst accessing one part of the PSU may recognise needs that will be met by other PSU resources, a confirmation of the Unit's 
holistic approach. It is a path. For example, a doctor seeking mentoring in order to develop his/her leadership skills may also have a significant career or mental health issue such as stress; some doctors seeking careers advice may benefit from support with language skills and cultural understanding. Shared knowledge across the PSU also increases awareness of changing factors in sustaining clinician performance and well-being.

Our experience has also confirmed that the key to progress and satisfaction for individual clinicians lies in recognition of their own realistic, step-by-step, personal development. We continue to produce materials to support this process by peer-to-peer group learning, including website testimonies of clients' stories.

We have also learned that a robust and careful framework of boundaries must be developed: for example, confidentiality is carefully maintained and any sharing of personal information and intelligence across the PSU is negotiated at the client's discretion, with due attention to considerations of candour (20) and patient safety.

In order for remediation to be effective it requires input in terms of provision of suitably trained and resourced case-workers with knowledge of the variety of individual and group learning opportunities the PSU offers for the clinician's plan for personal development. This provision of support comes from people with a range of skills and professional backgrounds who need appropriate supervision and support.

We have ensured that frameworks of support for the PSU workforce and quality assurance processes are in place as we extend our work to the wider workforce.

\section{Conclusion}

It has been important to build the service on strong fundamental values and principles. These are discussed in more detail by Whiteman and Jamieson (15) and Whiteman and King (17) and include:

1. Patient safety

2. Effective use of resources, networks and supervision

3. Application of adult learning principles and empowerment of the practitioner

4. Collaborative working with other organisations.

The PSU, separate from an employing organisation, providing a holistic, tailored service supporting professional values and behaviours, assists clinicians aiming for excellence in demanding times, as well as those with performance concerns. An important issue for the future will be to determine the responsibility for funding such a service (21).

The Academy of Medical Royal Colleges remediation working report (9) supports the proposal to establish Professional Support Units at a regional level to manage and coordinate programmes of remediation, drawing on the expertise of other organisations as and when required.
With the current changes in health professional education in England, the remit of our PSU has widened to include other professional groups and there is national interest in the possibilities of adopting the model elsewhere.

Looking to the future we need to widen our focus, continue to monitor the service provided, develop our quality assurance processes, evaluate our interventions and ensure costeffectiveness. As a multidisciplinary and multiprofessional group who work collaboratively we feel confident and primed to take this work forward.

\section{References}

1. Department of Health. Patients First and Foremost: The Initial Government Response to the Report of The Mid Staffordshire NHS Foundation Trust Public Inquiry, 2013. Available at: https://www.gov.uk/government/uploads/system/uploads/attachmen t_data/fil... (Accessed 12th April 2013)

2. Department of Health. Report by Steering Group on Remediation, 2011. Available from:

http://www.dh.gov.uk/en/Publicationsandstatistics/Publications/Publi cati...

3. Department of Health. Trust, assurance and safety: the regulation of health professionals in the 21st century, 2007. Available at:

http://www.officialdocuments.gov.uk/document/cm70/7013/7013.pdf (Accessed 12th April 2013)

4. How much does it cost to train a doctor in the United Kingdom? BMA January 2013. Available at: http://bma.org.uk/-/media/Files/Word\%20files/News\%20views\%20a nalysis/pre.... (Accessed 9th April 2013)

5. Cohen D, Rhydderch M, Cooper I. Managing remediation. Understanding medical education. Edinburgh: Association for the Study of Medical Education, 2007

6. General Medical Council. Good Medical Practice. General Medical Council; 2006

7. Williams BW. The prevalence and special educational requirements of dyscompetent physicians. Journal of Continuing Education in the Health Professions 2006;26 (3):173-91

8. Morison J, Irish B, Whiteman J. Professionalised educational appraisal and support for the struggling GP. Education for primary care 2012;23(6):374-7

9. Academy of Medical Royal Colleges. Remediation and Revalidation. Available from: URL: http://www.aomrc.org.uk/publications/statements/doc_view/63-reme diation-...

10 Kinnersley P, Edwards A. Complaints against doctors, BMJ. 


\section{BMJ Quality Improvement Reports}

2008 April 19; 336(7649): 841âप0842

11 Viney R. and Paice E. The First 500. A report on London Deanery's coaching and mentoring service 2008-2010. Available at: http://mentoring.londondeanery.ac.uk/news/the-first-500-a-newpublicatio...

12. Elton C. Careers Support. In Mckimm J and Swanwick (Eds). Clinical teaching made easy. A practical guide to teaching and learning in clinical settings, London: Quay Books; 2010

13. Rustecki L, Trafford $P$, Burrows $P$, Khan A. 'Assessing the communicative competence of EU General Practitioners applying to work in London'. Education for Primary Care 23 (3):220-4 (2012)

14. Thistlethwaite $J$. and Morris P. The Patient-Doctor Consultation in Primary Care: Theory and Practice. London: Royal College of General Practitioners; 2006.

15. Whiteman J, Jamieson A. Remediation with trust, assurance and safety. Education for Primary Care 2007;18(6):665-73

16. Meerten M, Bland J, Gross S, Garelick, A.I. Doctors' experience of a bespoke physician consultation service: cross-sectional investigation. The Psychiatrist 2011; 35: 206-212

17. Whiteman J and King J. Development of LD PSU. 2011.

Available at:

http://www.londondeanery.ac.uk/professionaldevelopment/professional-sup...

18. Prochaska JO, DiClemente CC. The transtheoretical approach: Towards a systematic eclectic framework. Homewood, IL: Dow Jones Irwin; 1984.

19. Harrison J. A future forum for UK occupational health? Occupational Medicine 2012;62:590âDL591

20. Francis R. Independent Inquiry into care provided by Mid Staffordshire NHS Foundation Trust. London: The Stationery Office; 2010

21. Swanwick T, Whiteman J. Remediation: where does the responsibility lie? Postgraduate medical journal 2013;89(1047):1-3.

\section{Declaration of interests}

Nothing to declare.

\section{Acknowledgements}

We would like to acknowledge with gratitude the helpful comments and contributions from David Mendel and Jocelyn Hewitt of the PSU; useful feedback from Naureen Bhatti and Rebecca Viney of the PSU and from Gerry Harris of the London Deanery's Appraisal and Revalidation team; valuable suggestions on style and content from Ernest Dalton, facilitator with the PSU.
Finally, we acknowledge the generous efforts of all who have worked so hard in the PSU to make it a success. 